\title{
POLYMORPHISMS MAINTAINED BY SEXUAL SELECTION IN MONOGAMOUS SPECIES OF BIRDS
}

\author{
PETER O'DONALD \\ Department of Genetics, University of Cambridge, Milton Road, \\ Cambridge CB4 $1 \mathrm{XH}$
}

Received 1.i.73

\begin{abstract}
Summary
A computer model has been developed of sexual selection in monogamous birds as a result of variations in fitness at breeding time. In the model, the females may prefer to mate with any of the three male genotypes, $A A, A a$ and $a a$, in a simple genetic polymorphism such as the different colour phases of the Arctic Skua.

Results are given for two different distributions of breeding times and fitnesses: (i) the distribution observed in the Arctic Skua, a polymorphic sea bird; (ii) normal distribution of breeding times with fitnesses decreasing as the square of the deviations from the mean.

In the computer simulations, values chosen for the female mating preference were either (i) additive, (ii) over-dominant, or (iii) " disruptive" with homozygotes preferred to heterozygotes.

When breeding times and fitnesses are distributed as in the Arctic Skua, both additive and over-dominant mating preferences give rise to selection for stable polymorphisms with similar gene frequencies at equilibrium to those in the corresponding models of selection in polygamous species. Disruptive mating preferences generally produce unstable equilibria, unlike the model for polygamy.

When breeding times are normal, the rarer allele is usually at a disadvantage and eliminated. But when mating preferences are very slight, the same equilibria are sometimes reached as in the polygamy model.
\end{abstract}

\section{IntRodUCtIon}

SEXUAL selection takes place when some males have an advantage over others in their ability to find mates. Their advantage may be gained as a result of female mating preferences for particular male phenotypes or in direct competition with other males. In polygamous species, the sexually superior males may obtain a great overall selective advantage by mating with a number of females. In monogamous species, however, they can only obtain a selective advantage by mating with females who on average will rear more offspring. Darwin (1871) argued that in birds the females who are ready to breed early in the breeding season do so because they are in a better nutritional condition and they will also rear more offspring for this reason. The males who are successful in mating with the earlier females thus obtain the advantage. O'Donald (1972a) analysed data on the breeding of the Arctic Skua, a polymorphic sea bird of the North Atlantic, and showed that very strong selection could occur if males of a particular phenotype were preferred by the females and mated first, since earlier pairs are much more successful in rearing the chicks. Berry and Davis (1970) analysed data showing that in newly formed pairs of birds the dark phased males were the first to breed. 
They would have a considerable selective advantage as a result of their early breeding (O’Donald, 1972c).

Computer models show that sexual selection must necessarily be frequencydependent in monogamous species (O'Donald, 1972b, 1973a). If the females prefer males of a particular phenotype, the proportion of the females mating according to their preferences then determines the nature of the frequencydependence. When this is only a small proportion of the females, the selective advantage of the preferred males declines sharply as they increase in frequency. The selection is therefore negatively frequency-dependent. It can lead to stable polymorphisms when balanced by natural selection. If most of the females exercise the preferences, the males' selective advantage rises rapidly until most males are of the preferred phenotype: the remaining males are then left to mate with the last females to breed who have much lower fitnesses. The computer models show that sexual selection can also take place even though the earlier breeding females are no fitter than the later breeding ones. Fitness may be symmetrically distributed around the mean breeding date for example, and yet an advantage can still be gained by males who are preferred by a small proportion of the females (O'Donald, 1972b).

There can be no doubt, however, that sexual selection will be more effective in a polygamous species. It produces a stable polymorphism if there are separate mating preferences for more than just one of the male genotypes (O'Donald, 1973b). Suppose that in a polymorphism determined by two alleles at a locus, a proportion, $\alpha$, of the females prefer to mate with $A A$ males, while $\beta$ prefer $A a$ and $\gamma$ prefer $a a$. If the genotypes $A A, A a$ and $a a$ are at frequencies of $u, v$ and $w$, and if the remaining proportion, $1-\alpha-\beta-\gamma$, of the females mate at random, the matings occur in the following proportions:

Males $\left\{\begin{array}{llll}A A & \alpha u+(1-\alpha-\beta-\gamma) u^{2} & \alpha v+(1-\alpha-\beta-\gamma) u v & \alpha w+(1-\alpha-\beta-\gamma) u w \\ A a & \beta u+(1-\alpha-\beta-\gamma) u v & \beta v+(1-\alpha-\beta-\gamma) v^{2} & \beta w+(1-\alpha-\beta-\gamma) v w \\ a a & \gamma u+(1-\alpha-\beta-\gamma) u w & \gamma v+(1-\alpha-\beta-\gamma) v w & \gamma w+(1-\alpha-\beta-\gamma) w^{2}\end{array}\right.$

It can then be shown (O'Donald, 1973b) that the gene frequency, $p=u+\frac{1}{2} v$, changes in the next generation by the amount

$$
\Delta p=\frac{1}{2} \phi-\frac{1}{2} \theta p
$$

where $\theta=\alpha+\beta+\gamma$ and $\phi=\alpha+\frac{1}{2} \beta$. Thus at equilibrium

$$
p_{e}=\phi / \theta \text {. }
$$

In general, after $n$ generations of selection, the gene frequency has become

$$
p_{n}=p_{e}\left\{1-\left(1-\frac{1}{2} \theta\right)^{n}\left(1-p_{o} / p_{e}\right)\right\}
$$

where $p_{o}$ is the gene frequency at the start of selection. The following results for particular mating preferences are worth mentioning. If $\beta=\frac{1}{2} \alpha$ and $\gamma=0$, the effects of the mating preferences can be described as additive on genotypes: at equilibrium $p_{e}=5 / 6$. If $\beta=2 \alpha$ the mating preferences are over-dominant: $p_{e}=2 / 3$. If the mating preferences are disruptive, such that $\beta=0$ and $\theta=\alpha$, then $p_{e}=1 / 2$. The rate of approach to these 
equilibria depends on $\theta$, the overall proportion of females who want to mate according to a preference for one or other of the males.

In a monogamous species, the effects of such mating preferences are necessarily much more complicated for they depend on the frequencies of both the preferring females and the preferred males. In previous computer models (O'Donald, 1972b, 1973a), only one of the male phenotypes was preferred: the females mated at random with the others. In this paper results are given of computer simulations in which all three male genotypes can be preferred separately by the females, as in the model of sexual selection in polygamous species. The actual computations are complicated and depend on the proportions of the different males available as mates at successive periods in the breeding season (O'Donald, 1973a). The mean selective coefficients of the different males are determined by the relation between breeding time and breeding success. Two distributions of breeding time and breeding success were used in the present computations. One was the empirical distribution of breeding time and breeding success observed in the Arctic Skua. In this distribution breeding time is skew with a long tail of late breeders: the pairs with the highest fitness are those breeding first (O'Donald, 1972a). The other distribution used was entirely hypotheticala normal distribution having the same variance as in the Arctic Skua, but with fitness distributed symmetrically around the mean breeding time.

\section{Selection by variation in breeding time in the Argtic Skua}

Table 1 shows the distribution of breeding time and relative fitness calculated from the breeding data of the Arctic Skua in a colony on Fair Isle, Shetland (O'Donald, 1972a). The earlier pairs have a much higher breeding

TABLE 1

Breeding dates and relative fitnesses of the Arctic Skua

$\begin{array}{ccc}\begin{array}{c}\text { Breeding periods } \\ \text { in weeks }\end{array} & \begin{array}{c}\text { No. of pairs breeding } \\ \text { in period }\end{array} & \text { Relative fitness } \\ \text { 10-16 June } & 20 & 0.99075 \\ \text { 17-23 June } & 114 & 0.98857 \\ \text { 24-30 June } & 61 & 0.90393 \\ \text { 1-7 July } & 23 & 0.73683 \\ \text { 8-14 July } & 3 & 0.48726\end{array}$

success than the later pairs. The Arctic Skua is genetically polymorphic with birds of pale, intermediate and dark phased plumage. If there are female preferences for the different phases of males (or if males of one phase are more successful than males of another phase in direct competition for the females), then the different phases of the males will show different distributions of breeding time: those breeding earlier will have the higher mean relative fitness. This has been observed among new pairs: the dark males breed on average before the intermediates who breed before the pales (Berry and Davis, 1970), thus giving the darks a considerable selective advantage (O'Donald, 1972c). The computer model of selection by variations in fitness at breeding time has been extended to allow for separate mating preferences for each of the genotypes $A A, A a$ and $a a$ of the males. The results can thus be compared with those of selection in a polygamous species, 
already described in the introduction. The mating preferences were either additive, over-dominant or disruptive, with particular examples as follows:

$\begin{array}{lcccc} & \overbrace{A A}^{A a} & a a & \begin{array}{c}\text { Equilibrium gene frequency } \\ \text { in polygamous species }\end{array} \\ \begin{array}{l}\text { Additive mating } \\ \text { preference }\end{array} & \frac{2}{3} \theta & \frac{1}{3} \theta & 0 & p_{e}=5 / 6 \\ \begin{array}{c}\text { Over-dominant mating } \\ \text { preference }\end{array} & \frac{1}{3} \theta & \frac{2}{3} \theta & 0 & p_{e}=2 / 3 \\ \begin{array}{c}\text { Disruptive mating } \\ \text { preference }\end{array} & \frac{1}{2} \theta & 0 & \frac{1}{2} \theta & p_{e}=1 / 2\end{array}$

As before, $\theta$ is the overall proportion of females who have mating preferences. The results of selection produced by these mating preferences have now been calculated using the extended computer model.

\section{(i) Additive mating preferences}

Results given in table 2 were computed for the particular values shown of the proportions of females having mating preferences for the three male genotypes. Except for the last set of values, when the total proportion of females mating by preference is $\theta=0.75$, the equilibrium reached is just the same as in the model for polygamy. The same results are also obtained

TABLE 2

Values, $\alpha, \beta$ and $\gamma$, of mating preferences for $\mathrm{AA}, \mathrm{Aa}$ and aa males showing the gene frequency reached at equilibrium from $\mathrm{p}_{\mathrm{o}}=0.001$

$\begin{array}{cllcc}\alpha & \beta & \gamma & \begin{array}{c}\text { Equilibrium } \\ \text { gene frequency }\end{array} & \begin{array}{c}\text { No. of generations } \\ \text { to equilibrium }\end{array} \\ 0.1 & 0.05 & 0 & 0.83334 & 3000 \\ 0.2 & 0.1 & 0 & 0.83334 & 2000 \\ 0.3 & 0.15 & 0 & 0.83333 & 900 \\ 0.4 & 0.2 & 0 & 0.83333 & 600 \\ 0.5 & 0.25 & 0 & 0.83598 & 400\end{array}$

using different initial values of the gene frequency of the allele $A$. Selection is of course much quicker in a polygamous species. For example if $\theta=0.15$, equilibrium is reached in about 190 generations, compared with about 3000 generations in a monogamous species. The actual progress of selection and the changes of the selective coefficients are shown in table 3.

Table 3 shows that while $A$ is at a low frequency it is selected as if it were dominant. At higher frequencies the selective coefficients are more or less additive. Near equilibrium the selective coefficients produce an advantage of the heterozygotes which ultimately maintains the equilibrium at $p_{e}=0.8333$. As shown in table 3 , when $\theta=0.15$ the selection is negatively frequencydependent with the selective coefficients decreasing as the preferred males increase in frequency. At high values of $\theta$, however, the selective coefficients increase with the frequency of the preferred males, the selection becoming positively frequency-dependent. This is in accordance with previous results (O’Donald, 1972b, 1973a).

Natural selection was also incorporated into the model. Selective 
coefficients of the same magnitude as the mating preferences acting against the preferred males inevitably prevent any sexual selection occurring, for the natural selective coefficients are initially greater than the sexual selective coefficients. If natural selection acts in favour of the preferred males, the final equilibria are reached at gene frequencies greater than 0.8333 , depending on the values of the natural selective coefficients.

TABLE 3

Progress of sexual selection when $\alpha=0.1, \beta=0.05$ and $\gamma=0$

\begin{tabular}{ccccc} 
& & \multicolumn{3}{c}{ Sexual selective coefficients } \\
Generation & $\begin{array}{c}\text { Gene } \\
\text { frequency }\end{array}$ & $A A$ & $A a$ & $a a$ \\
1 & 0.001 & 0 & 0 & $0 \cdot 05901$ \\
100 & 0.02004 & 0 & $0 \cdot 007569$ & $0 \cdot 06102$ \\
200 & 0.09760 & 0 & $0 \cdot 04544$ & $0 \cdot 06237$ \\
300 & $0 \cdot 2204$ & 0 & $0 \cdot 05456$ & $0 \cdot 06349$ \\
400 & 0.4341 & 0 & $0 \cdot 02880$ & $0 \cdot 03570$ \\
500 & 0.5970 & 0 & $0 \cdot 01221$ & $0 \cdot 01940$ \\
600 & 0.6935 & 0 & $0 \cdot 006276$ & $0 \cdot 01445$ \\
700 & 0.7506 & 0 & $0 \cdot 003061$ & $0 \cdot 01236$ \\
800 & 0.7844 & 0 & $0 \cdot 001027$ & $0 \cdot 01133$ \\
900 & 0.8044 & 0.000300 & 0 & $0 \cdot 01108$ \\
1000 & 0.8162 & 0.001152 & 0 & $0 \cdot 01161$ \\
2000 & 0.8333 & 0.002499 & 0 & $0 \cdot 01253$
\end{tabular}

\section{(ii) Over-dominant mating preferences}

In the model for a polygamous species, the equilibrium when $\beta=2 \alpha$ and $\gamma=0$ is established at $p_{e}=2 / 3$. In table 4 the equilibrium gene frequencies and selective coefficients at equilibrium are given for different values of $\theta=\alpha+\beta+\gamma$. Table 4 shows the frequency-dependence of the selection. Initially, when the gene frequency is $p_{o}=0.001$, the selective coefficients of the genotypes $A A, A a$ and $a a$ are 0,0 , and 0.05901 for all

TABLE 4

\begin{tabular}{|c|c|c|c|c|c|}
\hline \multirow[b]{3}{*}{$\begin{array}{l}\text { Values } \\
\text { of } \theta\end{array}$} & \multicolumn{5}{|c|}{ Over-dominant mating preferences with $\mathrm{p}_{\mathrm{o}}=0.001$} \\
\hline & \multirow{2}{*}{$\begin{array}{l}\text { Equilibrium } \\
\text { gene } \\
\text { frequency }\end{array}$} & \multirow{2}{*}{$\begin{array}{c}\text { Generations } \\
\text { to } \\
\text { equilibrium }\end{array}$} & \multicolumn{3}{|c|}{$\begin{array}{c}\text { Sexual selective coefficients at } \\
\text { equilibrium }\end{array}$} \\
\hline & & & $A A$ & $A a$ & $a a$ \\
\hline $0 \cdot 075$ & 0.6666 & 5000 & 0.003637 & 0 & $0 \cdot 007274$ \\
\hline $0 \cdot 15$ & $0 \cdot 6667$ & 3000 & $0 \cdot 007809$ & 0 & $0 \cdot 01562$ \\
\hline $0 \cdot 225$ & 0.6667 & 2000 & 0.01264 & 0 & $0 \cdot 02528$ \\
\hline $0 \cdot 3$ & 0.6667 & 1000 & $0 \cdot 01830$ & 0 & $0 \cdot 03660$ \\
\hline 0.6 & $0 \cdot 6702$ & 500 & $0 \cdot 04846$ & 0 & $0 \cdot 09847$ \\
\hline 0.9 & $0 \cdot 6881$ & 300 & $0 \cdot 06790$ & 0 & $0 \cdot 1498$ \\
\hline
\end{tabular}

values of $\theta$. When $\theta$ is small, the final selective coefficient of $a a$ has declined to about one-eighth of its initial value. When $\theta$ is large, it has increased to about three times its initial value. The frequency-dependence of the sexual selective coefficients is thus negative at low values of $\theta$ and positive at high values, again as in previous results.

Natural selection against the sexually preferred males can lead to polymorphic equilibria provided the natural selective coefficients are less than

$32 / 1-\mathrm{A} 2$ 
the initial sexual coefficients. Then for small values of $\theta$, the sexual selective coefficient declines until it exactly balances the natural selection (see O'Donald, 1973a). It is interesting that in this case, the overall selective coefficients may be negative and yet produce stable equilibria. Table 5 shows the results for different values of $\theta$ when the natural selective coefficients of $A A, A a$ and $a a$ are $0 \cdot 05,0.025$ and 0 . The equilibrium gene frequency is given correctly by the overall selective coefficients of natural and

TABLE 5

Natural selection with over-dominant mating preferences

$\begin{array}{lcccc}\begin{array}{c}\text { Values } \\ \text { of } \theta\end{array} & \begin{array}{c}\text { Equilibrium } \\ \text { gene } \\ \text { frequency }\end{array} & & \begin{array}{c}\text { Overall selective coefficients of natural } \\ \text { and sexual selection combined }\end{array} \\ 0.075 & 0.07106 & -0.01289 & 0 & -0.0009824 \\ 0.15 & 0.1999 & -0.01506 & 0 & -0.003762 \\ 0.225 & 0.3300 & 0.0007962 & 0 & 0.0003940 \\ 0.3 & 0.4194 & 0.01216 & 0 & 0.008783\end{array}$

sexual selection combined. But for the two smaller values of $\theta$, the equilibria should be unstable according to the simple theory of balanced polymorphism because the heterozygotes are at an overall disadvantage. The equilibria are stable, however, because the sexual selective coefficients are frequencydependent. At the equilibrium frequencies given in table 5, the sexual selective coefficients are more or less additive with $A$ as the advantageous allele. The overall selective coefficients of sexual and natural selection produce the heterozygous disadvantage. However an increase in frequency above equilibrium reduces the sexual selection and natural selection therefore pulls the gene frequency back towards equilibrium again. A decrease in frequency below equilibrium increases the sexual selection which pushes the frequency up towards equilibrium. The equilibria are thus stable.

\section{(iii) Disruptive mating preferences}

When the two homozygotes are the preferred males, an equilibrium is reached at $p_{e}=\frac{\alpha}{\alpha+\gamma}$ in the model for a polygamous species. If $\alpha=\gamma$,

$p_{e}=1 / 2$. In the model for a monogamous species, the effects of selection depend on the initial frequency. Table 6 shows what happens when the initial gene frequency of $A$ is $p_{o}=0 \cdot 01$. The heterozygotes are here at an overall disadvantage as expected. $A A$ is the most favoured genotype which is also to be expected because it is rare and the $A A$ males can all mate with the first females to breed and therefore gain the greatest selective advantage. However, the initial selective coefficients show there is an unstable equilibrium point at $p_{e}=0.0468$. Since this equilibrium is greater than $p_{o}$, the gene frequency declines and $A$ is finally eliminated. At these low frequencies the sexual selective coefficients are almost constant with no frequencydependent effect. Thus at a low initial frequency, $A$ is always eliminated whatever the value of $\theta$. Disruptive sexual selection only produces a stable equilibrium if the initial frequency is greater than the unstable equilibrium point given by the initial selective coefficients. Then the final equilibrium 
frequency is approximately the same as in the model for a polygamous species. Also, if natural selection favours the heterozygotes, it may be sufficient to increase the gene frequency to the point where sexual selection reinforces the natural selection and produces an equilibrium determined by the overall selective forces of sexual and natural selection.

\section{TABLE 6}

Disruptive sexual selection for $\mathrm{AA}$ and aa males when $\mathrm{p}_{\mathrm{o}}=0.01$ and
$\theta=0.1$

\begin{tabular}{clccc} 
Generation & $\begin{array}{c}\text { Gene } \\
\text { frequency }\end{array}$ & \multicolumn{3}{c}{ Sexual selective coefficients } \\
1 & $0 \cdot 01$ & 0 & 0.06188 & $a a$ \\
100 & 0.008812 & 0 & 0.06192 & 0.05884 \\
500 & $0 \cdot 005110$ & 0 & 0.06187 & $0 \cdot 05885$ \\
1000 & 0.002455 & 0 & 0.06187 & $0 \cdot 05888$
\end{tabular}

\section{SELECTION WHEN BREEDING TIMES ARE NORMALly Distributed}

Although earlier breeding pairs are the fitter in the Arctic Skua and several other species (see Lack, 1968), it would not be justified to assume this is a necessary condition in birds. Lack (1968) suggested that breeding times evolved by selection for the time when food is available for the young and the females can form eggs. If so, it does not follow that early breeding should in general be associated with high breeding success. If there is an optimum period when food is available and when the females can form eggs, then fitness might be symmetrically distributed around the mean and optimum breeding time. Breeding time may be determined partly by genetic factors. If so, then when the earlier breeders are the fitter as in the Arctic Skua population of Fair Isle, selection should produce a population with an earlier mean breeding time and ultimately a population with breeding times symmetrical around the optimum time. It is therefore worth investigating the selective forces that may be produced as a result of female mating preferences operating in a population in which no advantage can be gained from breeding early. The method used in previous papers (O'Donald, $1972 b, 1973 a$ ) was to set up a normal distribution of breeding times having the same variance as the Arctic Skua distribution. The relative fitness of the pairs was assumed to be proportional to the square of the deviation from the mean breeding time, which therefore had the highest fitness. The actual relation between the squared deviations and the fitnesses was the same as that for the Arctic Skua.

As shown in the previous papers, the preferred males can still gain an advantage, provided they mostly breed at around the mean breeding time. Thus, when female preferences are very slight, the preferred males gain an advantage because enough of them are left by the earlier females to mate later with the more numerous females breeding at the mean and optimum time. If the preferred males are common, they necessarily gain an overall advantage whatever the magnitude of the mating preferences.

\section{(i) Additive mating preferences}

When breeding times are normally distributed and fitnesses are symmetrical, the inital gene frequencies are an important factor in determining 
which allele has the overall advantage. Table 7 gives the results when $p_{o}=0.01$, and table 8 the results when $p_{o}=0 \cdot 1$. When the initial gene frequency of $A$ is 0.01 . the initial selective coefficients give an equilibrium point above the initial frequency for values of $\theta$ up to $0 \cdot 045$. The gene

TABLE 7

Additive mating preferences with initial gene frequency 0.01

\begin{tabular}{|c|c|c|c|c|c|}
\hline \multirow{2}{*}{$\begin{array}{l}\text { Values } \\
\text { of } \theta\end{array}$} & \multirow{2}{*}{$\begin{array}{l}\text { Gene frequencies } \\
\text { at } 1 \text { and } 10,000 \\
\text { generations }\end{array}$} & \multirow{2}{*}{$\begin{array}{l}\text { Equilibrium gene } \\
\text { frequencies given } \\
\text { by selective } \\
\text { coefficients }\end{array}$} & \multicolumn{3}{|c|}{ Selective coefficients of genotypes } \\
\hline & & & $A A$ & $A a$ & $a a$ \\
\hline 0.015 & $\begin{array}{l}0.01 \\
0.01702\end{array}$ & $\begin{array}{l}0.01985 \\
0.01703\end{array}$ & $\begin{array}{l}0 \cdot 1873 \\
0 \cdot 1329\end{array}$ & $\begin{array}{l}0 \\
0\end{array}$ & $\begin{array}{l}0.003794 \\
0.002303\end{array}$ \\
\hline $0 \cdot 03$ & $\begin{array}{l}0 \cdot 01 \\
0 \cdot 02404\end{array}$ & $\begin{array}{l}0 \cdot 02380 \\
0 \cdot 02404\end{array}$ & $\begin{array}{l}0 \cdot 2223 \\
0 \cdot 1338\end{array}$ & $\begin{array}{l}0 \\
0\end{array}$ & $\begin{array}{l}0 \cdot 005420 \\
0.003297\end{array}$ \\
\hline $0 \cdot 045$ & $\begin{array}{l}0.01 \\
0.02908\end{array}$ & $\begin{array}{l}0 \cdot 01725 \\
0 \cdot 02908\end{array}$ & $\begin{array}{l}0 \cdot 2414 \\
0 \cdot 1356\end{array}$ & $\begin{array}{l}0 \\
0\end{array}$ & $\begin{array}{l}0 \cdot 004236 \\
0 \cdot 004062\end{array}$ \\
\hline 0.06 & $\begin{array}{c}0.01 \\
0\end{array}$ & $\begin{array}{c}0.002154 \\
0\end{array}$ & $\begin{array}{l}0 \cdot 2504 \\
0 \cdot 3138\end{array}$ & $\begin{array}{c}0 \\
0 \cdot 01761\end{array}$ & $\begin{array}{c}0 \cdot 001618 \\
0\end{array}$ \\
\hline 0.075 & $\begin{array}{c}0 \cdot 01 \\
0\end{array}$ & $\begin{array}{l}0 \\
0\end{array}$ & $\begin{array}{l}0 \cdot 2602 \\
0 \cdot 3341\end{array}$ & $\begin{array}{l}0.001569 \\
0.03935\end{array}$ & $\begin{array}{l}0 \\
0\end{array}$ \\
\hline
\end{tabular}

frequency therefore increases to an equilibrium point given by the selective coefficients at this point. But above $0 \cdot 045$, the equilibrium point given by the initial selective coefficients is less than the initial gene frequency, which declines, selection eventually becoming directional with the elimination of $A$.

TABLE 8

Additive mating preferences with initial gene frequency $0 \cdot 1$

\begin{tabular}{|c|c|c|c|c|c|}
\hline \multirow{2}{*}{$\begin{array}{l}\text { Values } \\
\text { of } \theta\end{array}$} & \multirow{2}{*}{$\begin{array}{l}\text { Gene frequencies } \\
\text { at } 1 \text { and } 10,000 \\
\text { generations }\end{array}$} & \multirow{2}{*}{$\begin{array}{l}\text { Equilibrium gene } \\
\text { frequencies given } \\
\text { by selective } \\
\text { coefficients }\end{array}$} & \multicolumn{3}{|c|}{ Selective coefficients of genotypes } \\
\hline & & & $A A$ & $A a$ & $a a$ \\
\hline $0 \cdot 015$ & $\begin{array}{l}0 \cdot 1 \\
0.5913\end{array}$ & $\begin{array}{l}1 \cdot 0 \\
1 \cdot 0\end{array}$ & $\begin{array}{l}0 \\
0\end{array}$ & $\begin{array}{l}0 \cdot 001316 \\
0 \cdot 000287\end{array}$ & $\begin{array}{l}0.001738 \\
0.000454\end{array}$ \\
\hline $0 \cdot 03$ & $\begin{array}{l}0 \cdot 1 \\
0 \cdot 02405\end{array}$ & $\begin{array}{l}0.06618 \\
0.02404\end{array}$ & $\begin{array}{l}0 \cdot 01213 \\
0 \cdot 1338\end{array}$ & $\begin{array}{l}0 \\
0\end{array}$ & $\begin{array}{l}0.000860 \\
0.003298\end{array}$ \\
\hline $0 \cdot 045$ & $\begin{array}{l}0 \cdot 1 \\
0 \cdot 02908\end{array}$ & $\begin{array}{l}0 \cdot 05081 \\
0 \cdot 02908\end{array}$ & $\begin{array}{l}0 \cdot 02442 \\
0 \cdot 1356\end{array}$ & $\begin{array}{l}0 \\
0\end{array}$ & $\begin{array}{l}0.001307 \\
0.004062\end{array}$ \\
\hline $0 \cdot 06$ & $\begin{array}{l}0 \cdot 1 \\
0 \cdot 03272\end{array}$ & $\begin{array}{l}0.04823 \\
0.03272\end{array}$ & $\begin{array}{l}0 \cdot 03477 \\
0 \cdot 1386\end{array}$ & $\begin{array}{l}0 \\
0\end{array}$ & $\begin{array}{l}0 \cdot 001762 \\
0 \cdot 004688\end{array}$ \\
\hline 0.075 & $\begin{array}{l}0 \cdot 1 \\
0 \cdot 03514\end{array}$ & $\begin{array}{l}0.04857 \\
0.03515\end{array}$ & $\begin{array}{l}0 \cdot 04367 \\
0 \cdot 1431\end{array}$ & $\begin{array}{l}0 \\
0\end{array}$ & $\begin{array}{l}0 \cdot 002229 \\
0 \cdot 005213\end{array}$ \\
\hline
\end{tabular}

When $p_{o}=0 \cdot 1$, the initial selective coefficients give equilibrium values generally less than $0 \cdot 1$, and $A$ declines to an equilibrium for all values of $\theta$ up to 0.075 without $A$ being eliminated.

When $p_{o}=0.01$, and $\theta=0.015$, the gene frequency increases by 
directional selection, which eventually becomes very slow after 1000 generations. This suggests that the gene frequency may ultimately reach the polygamous species equilibrium, $p_{e}=5 / 6$. Computer simulations starting at $p_{o}=0.9$ all give equilibrium values of 0.8333 , suggesting that if selection starts at sufficiently high initial gene frequencies the equilibrium will be the same as in a polygamous species; this is an unrealistic condition however.

\section{(ii) Over-dominant mating preferences}

As in previous computer simulations, when mating preferences are overdominant, the values of the mating preferences were chosen as $\beta=2 \alpha$ and $\gamma=0$. Table 9 shows the gene frequencies reached after 10,000 generations when initial gene frequencies are 0.01 and $0 \cdot 1$. At the lower values of $\theta$,

TABLE 9

Over-dominant mating preferences with initial gene frequencies 0.01 and 0.1

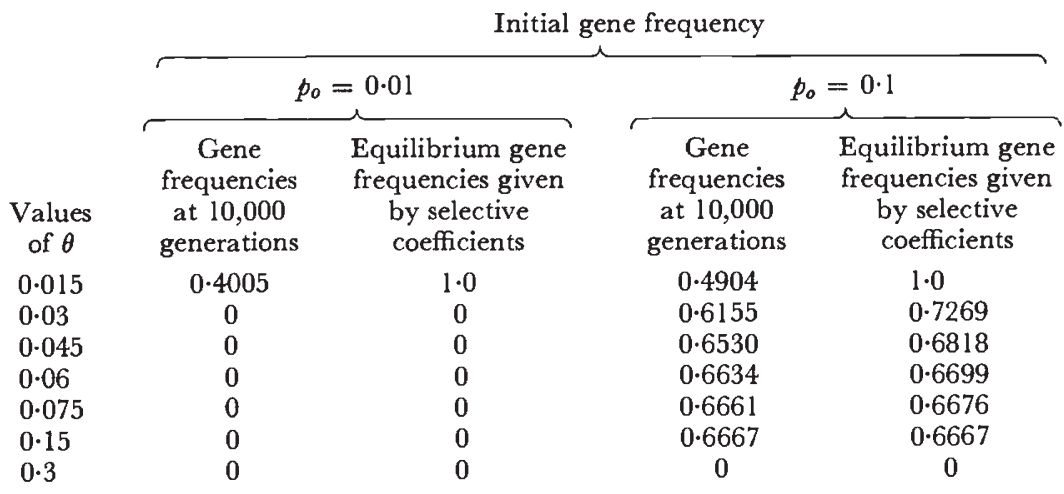

when selection becomes very slow, it is clear that equilibrium has not yet been reached. Closer to equilibrium the selective coefficients will presumably give the values of the final equilibrium more exactly. Thus, when $\theta=0.015$, at gene frequencies less than $p=0.5$, directional selection operates in favour of $A$ but only very slowly. It is to be expected that as $p$ increases further, an heterozygous advantage will develop and ultimately an

TABLE 10

Progress to final equilibrium

$\begin{array}{ccc}\text { Generation } & \begin{array}{c}\text { Actual gene } \\ \text { frequency }\end{array} & \begin{array}{r}\text { Equilibrium gene frequency } \\ \text { calculated from selective coefficients } \\ \text { at actual gene frequency }\end{array} \\ 5000 & 0 \cdot 4921 & 1 \cdot 0 \\ 6000 & 0 \cdot 5299 & 0 \cdot 896 \\ 7000 & 0 \cdot 5596 & 0 \cdot 823 \\ 8000 & 0 \cdot 5829 & 0 \cdot 777 \\ 9000 & 0 \cdot 6012 & 0 \cdot 748 \\ 10,000 & 0.6155 & 0 \cdot 727\end{array}$

equilibrium will be reached at approximately $p=2 / 3$. When $\theta=0.03$, the changes of the equilibrium gene frequency calculated from the selective coefficients at particular values of the actual gene frequency are as shown in table 10. It is reasonable to assume that the values of actual and equilibrium 
gene frequencies will eventually converge to the value $p_{e}=2 / 3$ in the model for polygamy. When $\theta=0 \cdot 15$, this convergence is complete.

\section{(iii) Disruptive mating preferences}

When mating preferences are disruptive and symmetrical, with $\alpha=\gamma$ and $\beta=0$, the rarer allele is generally eliminated. When mating preferences are not symmetrical, selection for the rarer allele can occur. For instance, if $A$ is at an initial frequency of $p_{0}=0.1$ and $\alpha=0.01, \beta=0$ and $\gamma=0.005$, then $A$ slowly increases to reach a frequency of 0.4490 after 10,000 generations. This selection occurs as a result of the heterozygotes being at a disadvantage. The selective coefficients give an unstable equilibrium gene frequency which remains less than the actual frequency. For values of $\alpha=0.02$ and $\gamma=0.01$ and higher such values, $A$ is always eliminated because the initial selective coefficients produce directional selection against $A$.

In general disruptive mating preferences do no produce stable equilibria in the model for monogamous species.

\section{ReFERENGES}

BERRY, R. J., AND DAVIS, P. E. 1970. Polymorphism and behaviour in the Arctic Skua (Stercorarius parasiticus (L.)). Proc. Roy. Soc. B, 175, 255-267.

DARWIn, c. 1871. The Descent of Man and Selection in Relation to Sex. John Murray, London. LACK, D. 1968. Ecological Adaptations for Breeding in Birds. Methuen, London.

O'DONALD, P. 1972a. Natural selection of reproductive rates and breeding times and its effect on sexual selection. Amer. Natur., 106, 368-379.

o'DONALD, P. 1972b. Sexual selection by variations in fitness at breeding time. Nature, 237, 349-351.

o'Donald, P. 1972c. Sexual selection for colour phases in the Arctic Skua. Nature, 238, 403-404.

o'DONALD, P. 1973a. Frequency dependent sexual selection as a result of variations in fitness at breeding time. Heredity, 30, 351-368.

o'DONALD, P. 1973b. Models of sexual and natural selection in polygamous species. Heredity, 31, 145-156. 